\title{
Wybrane zagadnienia stosowania odpornych na zużycie płyt w przemyśle wydobywczym
}

\author{
Selected issues of applying \\ a wear-resistant plates in the mining industry
}

\section{Streszczenie}

W pracy przedstawiono zagadnienie zabezpieczania powierzchni narażonych na ścieranie pracujących w warunkach kopalni odkrywkowej. Zebrano informacje o najpowszechniej stosowanych materiałach na elementy zabezpieczające przed nadmiernym zużyciem ściernym. Podjęto charakterystykę materiałów hutniczych oraz materiałów wytwarzanych w procesach napawania prewencyjnego $z$ zastosowaniem drutów rdzeniowych.

Opisano zastosowanie poszczególnych materiałów wraz z ich charakterystyką dotyczącą własności i struktury. Szczególnie skupiono się na elementach wykonanych technikami spawalniczymi z wykorzystaniem drutów rdzeniowych.

Słowa kluczowe: zużycie; zastosowanie; druty proszkowe; Fe-Cr-C; Hardox

\begin{abstract}
The paper presents the problem of protection of surface exposed to abrasion working in the conditions of the open -cast mine. Information on the most commonly used materials for abrasive wear protection has been collected. The characteristics of metallurgical materials and materials produced in the preventive surfactant processes using core wires were taken. The use of individual materials has been described together with their properties and structure characteristics. Particularly focused on elements made by welding techniques using core wires.
\end{abstract}

Keywords: wear; application; flux cored wires; Fe-Cr-C; Hardox

\section{Wprowadzenie}

Wśród zidentyfikowanych przyczyn zużycia występujących w przemyśle możemy określić, że największy udział blisko $50 \%$ występuje w wyniku zużycia ściernego. Następną przyczyną jest zużycie adhezyjne, którego udział jest na poziomie $15 \%$. Zużycie erozyjne i fretting stanowi ok. $8 \%$ przyczyn zużycia, korozja - ok. $5 \%$, a za pozostałe $14 \%$ odpowiada połączone oddziaływanie kilku procesów. Na wypadkową zużycia wpływa wiele czynników. Najważniejsze zostały przedstawione za pomocą diagramu Ischikawy (rys. 1) [1].

\section{Blachy hutnicze a warstwy napawane}

Analizując czynniki mogące mieć wpływ na własności technologiczne można wyróżnić kilka, które będą determinowały trwałość elementów i urządzeń. Ze względu na intensywność procesów zużycia i ogromnych mas skalnych transportowanych w kopalniach różnego rodzaju zsypami

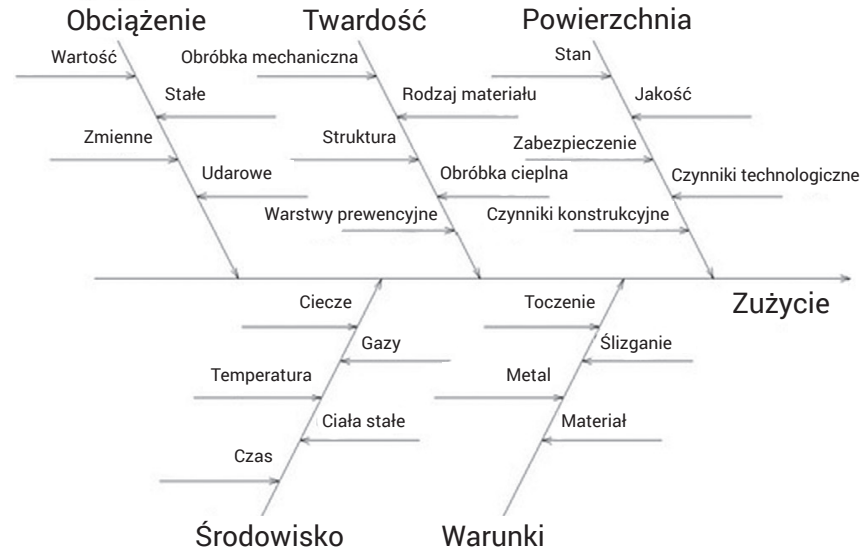

Rys. 1. Czynniki wpływające na zużycie

Fig. 1. Factors influencing on wear

Dr inż. Robert Bęczkowski - Politechnika Częstochowska.

Autor korespondencyjny/Corresponding author. rbeczkowski@spaw.pcz.pl 
i przesypami, elementy te są bardzo mocno narażone na gwałtowne zużycie. Rozwój technologii wydobywczych wymuszał szukanie najlepszych rozwiązań minimalizujących zużycie. Pierwsze próby podniesienia odporności na zużycie elementów przesypów polegały na zmianie struktury materiałów podstawowych w wyniku powierzchniowego hartowania. Kolejnym etapem było zastosowanie elementów hutniczych o większej twardości struktury materiału oraz zabezpieczenie powierzchni poprzez napawanie. W pierwszym etapie rozwoju procesów napawania były wykorzystywane elektrody otulone. Wraz z rozwojem materiałów dodatkowych coraz powszechniejsze stało się wykorzystanie drutów rdzeniowych, które pozwalały uzyskać napoiny o strukturze żeliw chromowych.

W literaturze można znaleźć publikacje opisujące zastosowanie drutów rdzeniowych jako alternatywę dla materiałów hutniczych. Blachy trudnościeralne charakteryzują się znacznie mniejszymi wskaźnikami odporności na zużycie (liniowe, objętościowe i wagowe) niż specjalne stopy metalurgiczne wykorzystujące współczesną inżynierię materiałową do podnoszenia trwałości elementów. Podniesienie odporności realizowane jest w głównej mierze poprzez zastosowanie wysokochromowych żeliw z udziałem złożonych twardych faz takich jak: $\mathrm{Cr}_{7} \mathrm{C}_{3}, \mathrm{Cr}_{23} \mathrm{C}_{6}, \mathrm{Cr}_{3} \mathrm{C}, \mathrm{NbC}, \mathrm{Nb}_{2} \mathrm{C}, \mathrm{VC}$ osadzonych w strukturze eutektycznej lub martenzytycznej. Druty rdzeniowe dają możliwość zastosowania twardych faz węglikowych do tworzenia warstw trudnościeralnych. Najczęściej w przypadku zakładów górniczych wykorzystuje się materiały oparte o stopy Fe-Cr-C z dodatkami Nb, V, B, które dają możliwość uzyskania twardości dochodzących do 68 HRC już w pierwszej warstwie przy zastosowaniu odpowiednich parametrów procesu napawania [1 13].

W zależności od warunków pracy danego urządzenia lub wybranych miejsc stosuje się określone zasady technologicznie (trwałość, możliwość aplikacji) i ekonomicznie (koszty wytworzenia i eksploatacji), którymi należy się kierować przy wyborze materiału dodatkowego i metody regeneracji czy prewencji. Nie zawsze jest uzasadnione stosowanie technologii spawalniczych do uzyskiwania warstw zabezpieczających, czasami wystarcza zastosowanie odpowiednich materiałów hutniczych, takich jak blachy trudnościeralne np. typu Hardox. Korzystna struktura wpływająca na podniesienie odporności na zużycie ścierne i określona twardość dostarczają oczekiwaną trwałość za rozsądną cenę. W obecnej chwili są dostępne na rynku blachy trudnościeralne o grubości od 0,7 do $160 \mathrm{~mm}$. W ostatnim czasie można zauważyć silny rozwój hutniczych materiałów trudnościeralnych. Pojawiły się blachy trudnościeralne o gwarantowanej udarności, czy zwiększonej odporności na pękanie naprężeniowe. Coraz częściej spotykamy się z zastosowaniem blach typu Xtreme o twardości ok. 60 HRC dostępnych w grubościach od 9 do $19 \mathrm{~mm}$, zbliżających się parametrami do blach napawanych [15].
Tablica I zawiera dane maksymalnych zawartości składników chemicznych wybranych trudnościeralnych materiałów hutniczych wraz z wartością równoważnika węgla $\mathrm{CEV}=\mathrm{C}+\mathrm{Mn} / 6+(\mathrm{Cr}+\mathrm{Mo}+\mathrm{V}) / 15+(\mathrm{Cu}+\mathrm{Ni}) / 15$ oraz twardością materiału $w$ stanie dostawy.

Istotną kwestią stosowania tych blach jest możliwość ich obróbki gięcia, wiercenia oraz spawania $[1,10]$.

Kwestia gięcia jest ważnym elementem technologicznym (rys. 2). Przy gięciu trudnościeralnych materiałów hutniczych problemem technologicznym jest określenie minimalnego promienia gięcia. W przypadku materiałów napawanych istotnym aspektem technologicznym jest sposób zwijania. Warstwa napawana ze względu na swoje własności użytkowe, tj. twardość i naprężenia spawalnicze oraz możliwość występowania pęknięć, może być zwijana tylko do środka, gdzie naprężenia rozciągające występują w warstwie bazowej najczęściej wykonanej z materiału gatunku S235. Przykład pokazano na rysunku $3[1,10,15]$.

W obecnej chwili nie jest problemem wiercenie w materiałach hutniczych (rys. 4), lecz w przypadku płyt napawanych konieczne staje się korzystanie z technologii cięcia plazmą, strumieniem wody lub koniecznością jest zastosowanie mocowania do konstrukcji za pomocą kołków zgrzewanych lub spawanych.

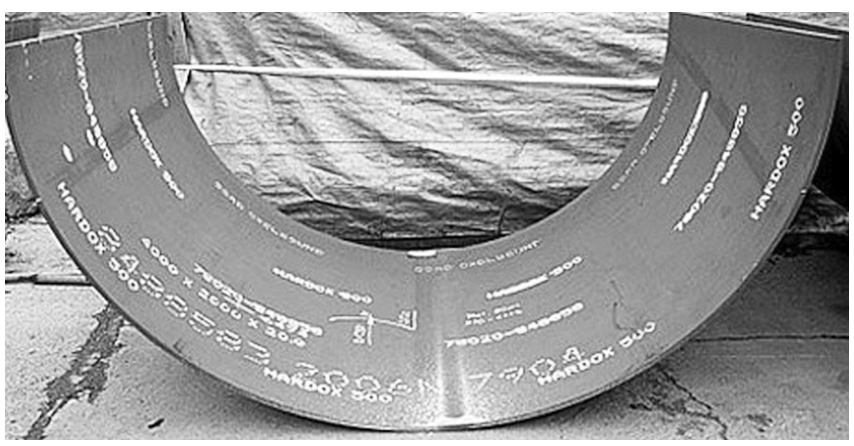

Rys. 2. Blacha trudnościeralna Hardox 500 kształtowana na zimno [16] Fig. 2. Wear plate Hardox after cold rolled [16]

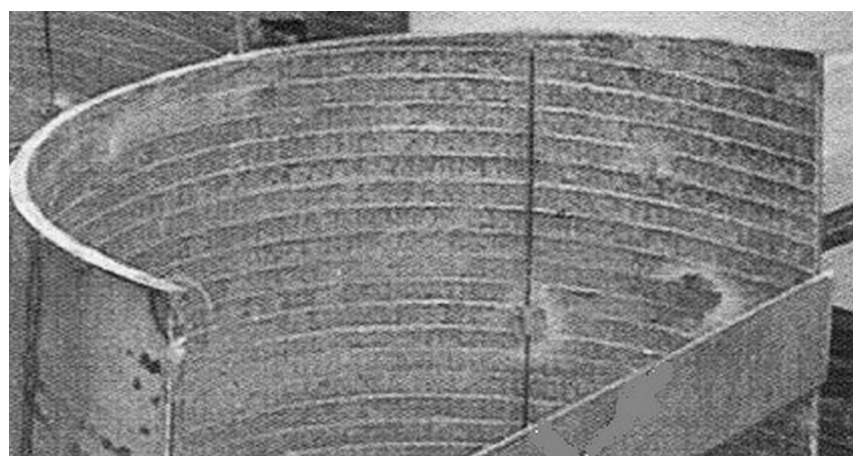

Rys. 3. Wykładziny napawane kształtowane na zimno [16] Fig. 3. Cold rolled of hardfacing plate [16]

Tablica I. Skład chemiczny blach trudnościeralnych [15] Table I. Chemical composition of wear plate [15]

\begin{tabular}{|c|c|c|c|c|c|c|c|c|c|c|c|}
\hline & \multicolumn{9}{|c|}{ Max. zawartość pierwiastka chemicznego [\%] } & \multirow{2}{*}{ CEV } & \multirow{2}{*}{ HBW } \\
\hline & C & Si & $M n$ & $\mathbf{P}$ & S & $\mathrm{Cr}$ & $\mathrm{Ni}$ & Mo & B & & \\
\hline Hardox 400 & 0,32 & 0,70 & 1,60 & 0,025 & 0,01 & 1,40 & 1,50 & 0,60 & 0,004 & 0,39 & $370-430$ \\
\hline Hardox 500 & 0,27 & 0,50 & 1,60 & 0,025 & 0,01 & 1,20 & 0,25 & 0,25 & 0,005 & 0,46 & $470-530$ \\
\hline Hardox 600 & 0,47 & 0,70 & 1,40 & 0,015 & 0,01 & 1,20 & 2,50 & 0,70 & 0,005 & 0,61 & $550-640$ \\
\hline Extreme & 0,47 & 0,50 & 1,40 & 0,015 & 0,01 & 1,20 & 2,50 & 0,80 & 0,005 & 0,54 & $650-700$ \\
\hline
\end{tabular}




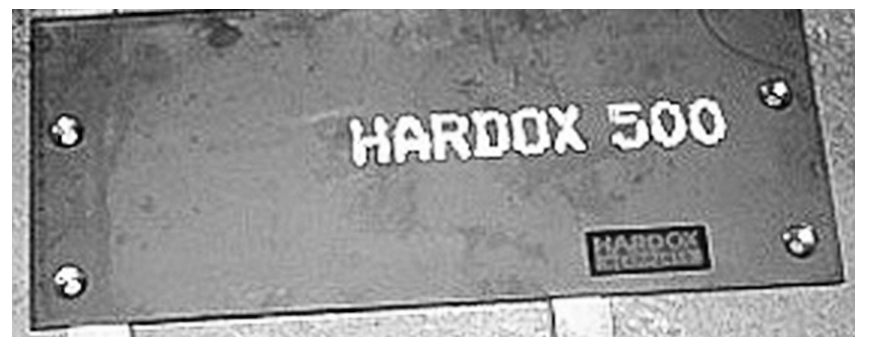

Rys. 4. Blacha trudnościeralna Hardox 500 po otworowaniu [16] Fig. 4. Wear plate Hardox after drilling [16]

W przypadku spawania blach trudnościeralnych istotne jest kontrolowanie temperatury podgrzewania, temperatury międzyściegowej, ilości wprowadzanego ciepła oraz kolejności spawania. Należy zwrócić uwagę na maksymalne dopuszczalne normami wielkości odstępów między materiałami łączonymi. Dla procesu spawania ważnym czynnikiem jest ilość wprowadzonego ciepła, która zwiększa obszar strefy wpływu ciepła (HAZ) i negatywnie wpływa na własności mechaniczne zmniejszając odporność na ścieranie strefy przegrzanej $[1,10,14,15]$.

Spawanie przy zastosowaniu niskiej ilości wprowadzanego ciepła pozwala uzyskać mniejsze odkształcenia, zwiększa się udarność i wytrzymałość złącza oraz podnosi odporność strefy przegrzanej na ścieranie. Jednakże materiały hutnicze są również wrażliwe na bardzo niską ilość wprowadzanego ciepła przy spawaniu, która powoduje wzrost szybkości studzenia w zakresie czasu t $t_{8 / 5}$ poniżej 3 sekund. Wówczas skutkuje to obniżeniem udarności [15].

Rysunek 5 pokazuje zalecane przez producenta maksymalne ilości wprowadzanego ciepła dla stali trudnościeralnych, by zachować ich założone własności użytkowe. Szczegóły dotyczące wstępnego podgrzewania można znaleźć na stronie producenta [15].

Należy pamiętać, iż temperatura miedzyściegowa nie powinna przekraczać dopuszczalnych wartości określonych przez producenta. Ograniczenie temperatury miedzyściegowej dotyczy wszystkich typów trudnościeralnych materiałów hutniczych. W większości przypadków temperatura jest ograniczona do $225^{\circ} \mathrm{C}$. Jednakże dla stali typu Extreme ograniczenie jest wprowadzone na poziomie $100^{\circ} \mathrm{C}$, a dla stali typu HardoxHiTuf ograniczenie temperatury miedzyściegowej jest do poziomu $300{ }^{\circ} \mathrm{C}[15]$.

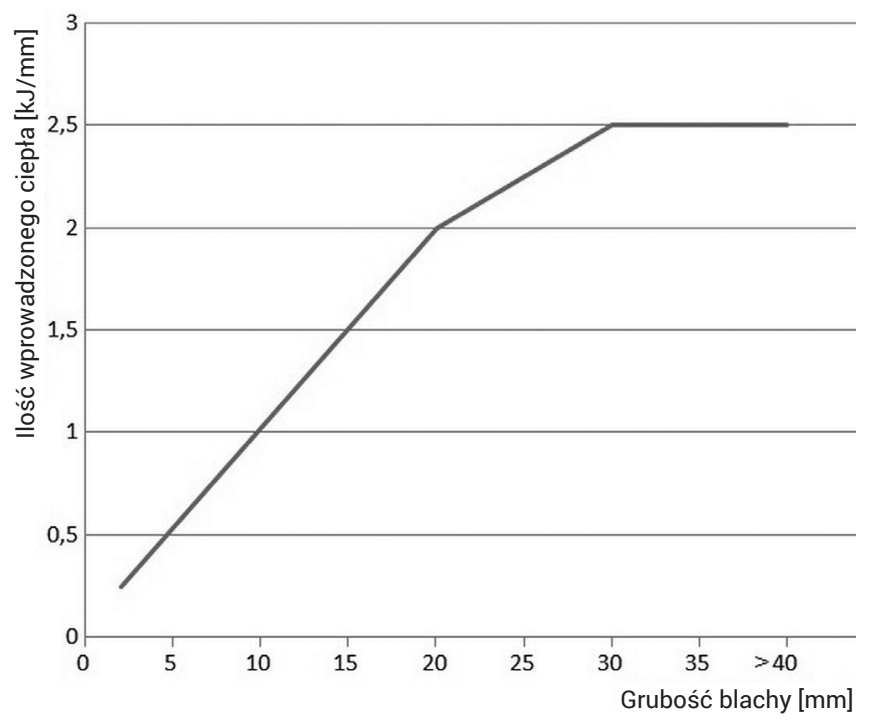

Rys. 5. Zalecane maksymalne ilości wprowadzonego ciepła przy spawaniu [15]

Fig. 5. Recommended maximum heat input during welding [15]
Przy zastosowaniu płyt trudnościeralnych istotnym czynnikiem są warunki pracy płyty. Na przykładzie zsuwni koła czerpakowego można pokazać trzy obszary (rys. 6), o różnej intensywności zużycia ściernego. Od obszaru o największej intensywności zużycia (oznaczono na rys. 6 jako 1), do obszaru o najmniejszej intensywności zużycia (oznaczono na rys. 6 jako 3 ).

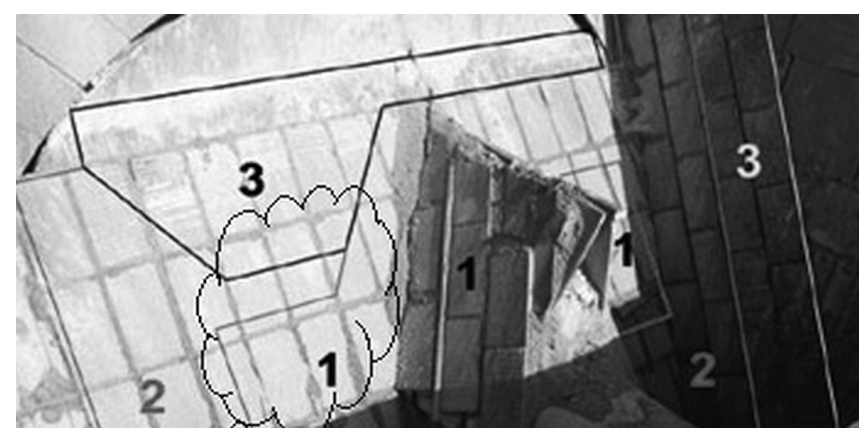

Rys. 6. Obszary zsuwni o różnej intensywności zużycia ściernego [16] Fig. 6. Areas of chopper with different abrasive wear intensity [16]

W obszarze o największej intensywności zużycia, trwałość jest określona średnio na około 800 godzin, w obszarze średniego zużycia na ok. 1250 godzin, a w obszarze o najmniejszej intensywności na 3600 godzin. Analogicznie do tego dobiera się materiały na wykładziny. Przykład badań materiałów hutniczych w warunkach rzeczywistych (rys. 7) pokazano dla obszaru rysunku 6 zaznaczonego chmurą. Materiały typu Hardox400 i Hardox500 wykazały znacznie większe zużycie, niż warstwy napawane stopami na bazie Fe-C-Cr.

Płyty napawane są wymieniane po zużyciu ok. $50 \%$ powierzchni napoiny. Wykładziny ze stali Hardox mogą być eksploatowane do zupełnego starcia zachowując własności w całym okresie eksploatacji, również lepiej wytrzymują one obciążenia dynamiczne pochodzące od urobku. Nie wykazują uszkodzeń powierzchni, które występują przy zastosowaniu płyt napawanych, takich jak odsłonięcia powierzchni w wyniku odpryśnięcia napoiny.

Proces spawania i procesy pokrewne są kwalifikowane jako procesy specjalne i koniecznym staje się zweryfikować zastosowaną technologię napawania według przyjętych standardów. W tym przypadku za taki standard można

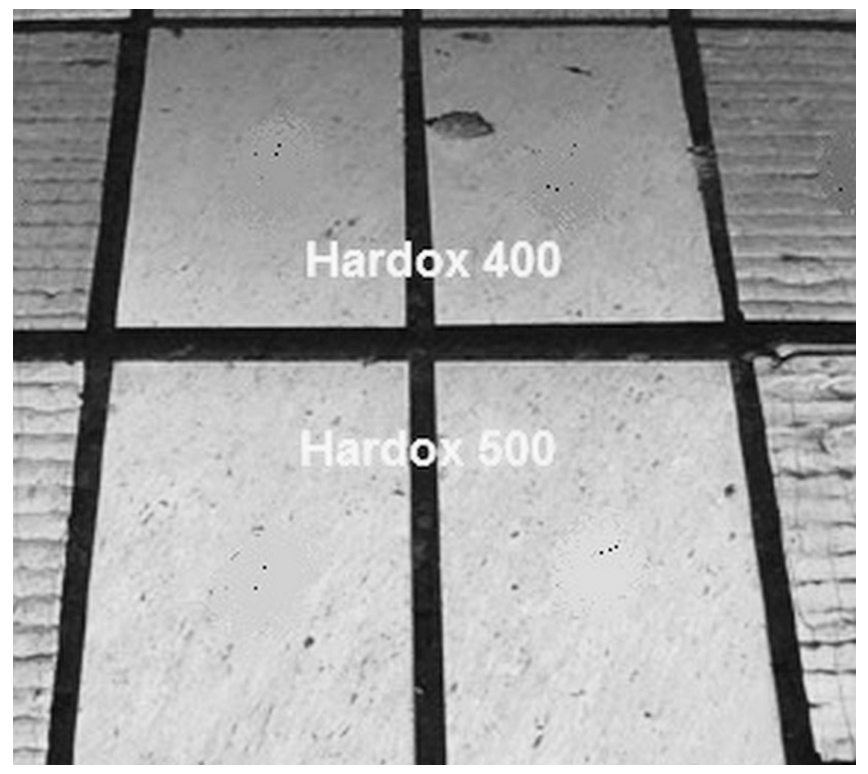

Rys. 7. Schemat rozmieszczenia płyt trudnościeralnych [16] Fig. 7. Scheme layout of wearplates [16] 
uznać PN EN ISO 15614-7. Jednakże zastosowanie tej normy $w$ przypadku napawanych warstw trudnościeralnych niesie za sobą trudności związane z wymaganiami tej normy i każdorazowo należy ustalić warunki odbioru technologii z klientem. W aspekcie odbiorowym warstwy napawane mogą stanowić problem dla przeprowadzenia inspekcji zgodnie z normami jakościowymi i dopuszczalnymi poziomami jakości, nie pozwalają na odbiór płyt napawanych bez uwag. Jednakże występujące niezgodności spawalnicze w postaci regularnych pęknięć, przyczyniają się do zmniejszenia naprężeń w elemencie napawanym $[1,3,10,17 \div 19]$.

Prowadzono próby służące do określenia własności warstw napawanych szczególnie twardości i struktury materiału jako czynników w głównej mierze odpowiadających za odporność na zużycie ścierne [1\%9].

Rysunki poniżej przedstawiają struktury: z wydzieleniami węglików chromu i niobu (rys. 8) oraz wymieszania w warstwie napawanej między ściegami napoiny Fe-Cr-C (rys. 9). $\mathrm{Na}$ rysunku 10 przedstawiono wyraźny układ kierunkowy wytworzonych węglików związany z wymuszonym odbiorem ciepła dającym korzystny układ ułożenia węglików w osnowie oraz niezgodność w postaci pęknięcia tzw. relaksacyjnego kończącego się na linii wtopienia.

Strefa wymieszania w przypadku płyt trudnościeralnych jest niewielka i zawiera się od kilku do kilkunastu procent. Zależy ona w głównej mierze od zastosowanych parametrów napawania. Między innymi z powodu małego wtopienia proces gięcia należy prowadzić tak, by napoina była ściskana. $W$ innym przypadku prowadzi to do odspojenia napoiny od materiału podłoża (rys. 11).

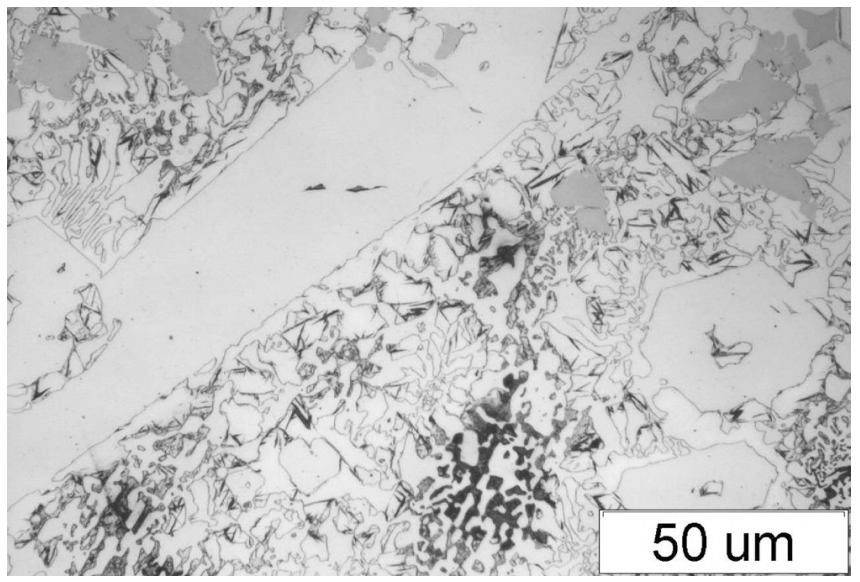

Rys. 8. Struktura z wydzieleniami węglików chromu i niobu Fig. 8. The structure of precipitates of chromium and niobium carbides

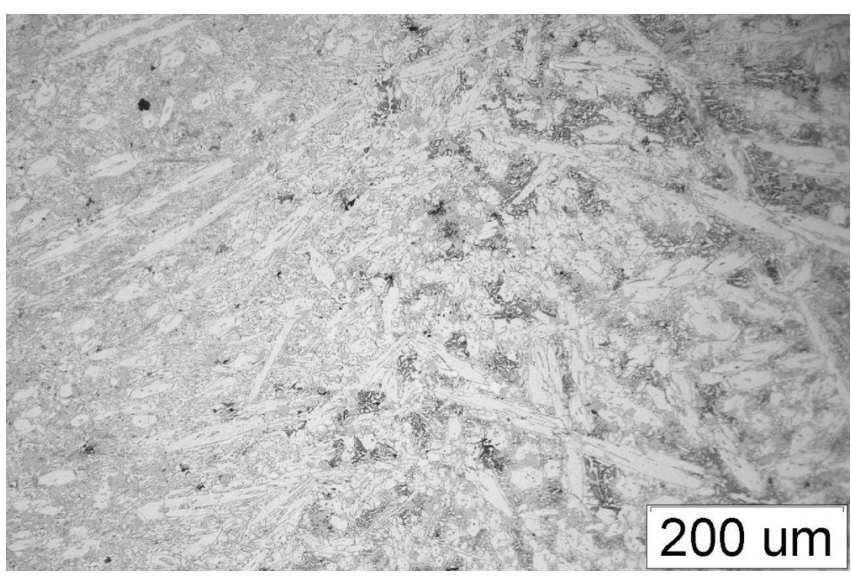

Rys. 9. Strefa wymieszania napoiny

Fig. 9. Weld mixing zone

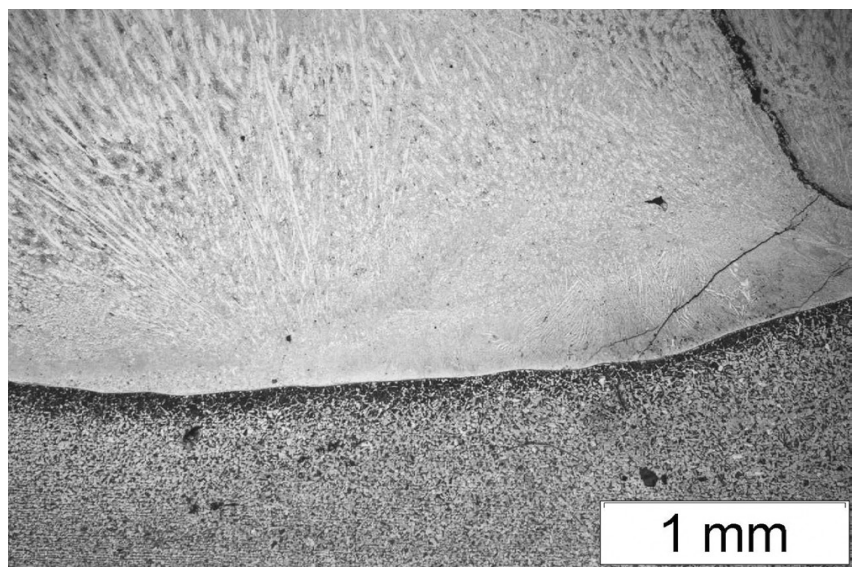

Rys. 10. Struktura napoiny z niezgodnościami spawalniczymi Fig. 10. Structure with weld imperfections

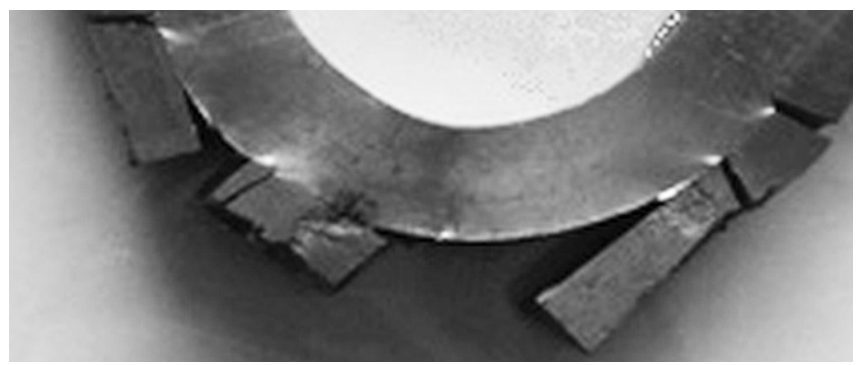

Rys. 11. Widok płyty napawanej po gięciu [1]

Fig. 11. View of a hardfacing plate after bending [1]

\section{Podsumowanie}

Pomimo licznie występujących niezgodności warstwy trudnościeralne wykonane przy wykorzystaniu technologii napawania automatycznego z użyciem drutów rdzeniowych o złożonym składzie chemicznym rdzenia są najkorzystniejszym rozwiązaniem stosowanym w przemyśle górniczym. Specyficzne własności związane w bardzo wysoką twardością i złożoną strukturą pozwalają na zastosowanie tych materiałów w miejscach najbardziej narażonych na zużycie ścierne luźnym ścierniwem. W przedstawionym studium przypadków zebrano praktyczne zastosowania warstw trudnościeralnych i przedstawiono alternatywę dla nich w postaci coraz intensywniej rozbudowującej się gamy materiałów hutniczych. Płyty trudnościeralne walcowane są relatywnie tańszym rozwiązaniem dla warstw napawanych. Zaletą ich jest praca do całkowitego zużycia. W przypadku płyt napawanych użytkowanie jest ograniczone do grubości warstwy napawanej. Zastosowanie płyt napawanych w znacznej mierze podnosi ciężar całkowity konstrukcji i wymusza bardziej masywną bazę montażową, jednakże daje najwyższą odporność na zużycie ścierne.

Zastosowanie materiałów trudnościeralnych pozwala na maksymalizację okresów między kolejnymi naprawami, poprzez modułowe rozwiązania minimalizuje się również koszty wymiany elementów i czyni je łatwiejszymi ze względu na zmniejszenie gabarytów i masy elementów. 


\section{Literatura}

[1] R. Bęczkowski, M. Gucwa: Kwalifikowanie napawania warstw trudnościeralnych pracujących w warunkach przemysłu cementowego, Przegląd Spawalnictwa, vol. 87(9), s. 43-46, 2015.

[2] M. Gucwa, R. Bęczkowski: Odporność na erozyjne zużycie strumieniowe napoin wykonanych drutem proszkowym samo osłonowym przy kącie padania ścierniwa $60^{\circ}$, Przegląd Spawalnictwa, vol. 83(10), s. 77-81, 2011.

[3] R. Bęczkowski: Właściwości wykładzin trudnościeralnych stosowanych na elementy przesypowe wykonane techniką napawania drutem rdzeniowym, Politechnika Częstochowska, Częstochowa 2007.

[4] R. Bęczkowski: Effect of cladding parameters on the hardness of bimetal plates, Metalurgija, vol. 56(1-2), pp. 59-62, 2017.

[5] R. Kejžar: Study of the alloying of a surfacing weld in the surfacing of wear-resistant deposits with alloyed welding fluxes, Materiali in Tehnologije, vol.37, 3-4, pp. 167-172, 2003.

[6] I. Pernis, J. Kasala, D. Žabecká: Resistance of weldclads made by fluxcoredarcwelding technology again sterosivewear, Metalurgija, vol.52, 3, pp. 352-354, 2013.

[7] P. F. Mendez, N. Barnes, K. Bell, S. D. Borle, S. S. Gajapathi, S. D. Guest, H. Izadi, A. K. Gol, G.Wood: Welding processes for wear-resistant overlays. Journal of Manufacturing Processes, vol.16, pp. 4-25, 2014.

[8] J. Niagaj: Effectof niobium on properties of hardfaced layers surface weIded by Fe-Cr-C open arc flux-coredwire electrodes, Przegląd Spawalnictwa, vol. 83(10), pp. 67-72, 2011.

[9] R. Bęczkowski, M. Gucwa, J. Wróbel, A. Kulawik: The Impact of the Bead Width on the Properties of the Anti Abrasion Surfacing Weld, International Conference of Numerical Analysis and Applied Mathematics 2015 (ICNAAM 2015), AIP Conf. Proc. 1738, 480095-1-480095-4; doi: 10.1063/1.4952331, 2015.
[10] R. Bęczkowski, M. Gucwa: Defects Appearing in the Surfacing Layersof Abrasion Resistant, Archives of Foundry Engineering, vol.16(4), pp. 23-28, 2016

[11] W. Orłowicz, V. Shevelyaa, A. Trytek, V. Kirilkov: Effect of the concentrated heat flowtreatment on the structure and the antiwearproperties of cast iron, Archives of Foundry Engineering, vol.9(2), pp. 185-188, 2009.

[12] M. Adamiak, J. Górka, T. Kik: Structure analysis of welded joint sofwearresistant plate and constructionalsteel, Archives of Materials Science and Engineering, vol.56(2), pp. 108-114, 2010.

[13] D.K. Dwivedi: Microstructure and abrasivewearbehaviourof iron base hardfacing, Materials Science and Technology, vol. 20, pp.1326-1330, 2004.

[14] J. Winczek: Modeling ofheataffectedzone in multipass GMAW surfacing S235 steel element, Procedia Engineering, vol.136, pp. 108 - 113, 2016.

[15] https://www.ssab.com/products/brands/hardox

[16] M. Wojdala: Wykładziny trudnościeralne stosowane do zabezpieczenia części maszyn narażonych na intensywne zużycie, Politechnika Częstochowska, Częstochowa 2012

[17] PN EN ISO 15614-7, Specyfikacja i kwalifikowanie technologii spawania metali - Badanie technologii spawania - Część 7: Napawanie.

[18] PN-EN ISO 6520-1:2009, Spawanie i procesy pokrewne. Klasyfikacja geometrycznych niezgodności spawalniczych w metalach. Część 1: Spawanie

[19] PN-EN ISO 5817:2014, Spawanie. Złącza spawane ze stali, niklu, tytanu i ich stopów (z wyjątkiem spawanych wiązką). Poziomy jakości według niezgodności spawalniczych. 